\title{
PENIPUAN DALAM URUS NIAGA TANAH DI MALAYSIA: SATU KAJIAN
}

\section{(Fraud in Land Dealings in Malaysia: A Study)}

\author{
Noraida Harun* \\ noraida@unisza.edu.my \\ Noor 'Ashikin Hamid \\ shikin@unisza.edu.my \\ Asiah Bidin \\ asiah@unisza.edu.my
}

Kamaliah Salleh

kamaliahsalleh@unisza.edu.my

Fakulti Undang-undang dan Hubungan Antarabangsa, Universiti Sultan Zainal Abidin.

Pengarang koresponden (Corresponding author): *

Rujukan artikel ini (To cite this article): Noraida Harun, Noor 'Ashikin Hamid, Asiah Bidin \& Kamaliah Salleh. (2022). Penipuan dalam urus niaga tanah di Malaysia: Satu Kajian. Kanun: Jurnal Undang-undang Malaysia, 34(1), 97-112. http://doi.org. 10.37052/kanun.34(1)no5

\begin{tabular}{|llllll|}
\hline $\begin{array}{l}\text { Peroleh: } \\
\text { Received: }\end{array} \quad$ 1/11/2021 & $\begin{array}{l}\text { Semakan: } \\
\text { Revised }\end{array} \quad 20 / 12 / 2021$ & $\begin{array}{l}\text { Terima: } \\
\text { Accepted: 27/12/2021 }\end{array}$ & $\begin{array}{l}\text { Terbit dalam talian: } \\
\text { Published online }\end{array}$ & 2/1/2022 \\
\hline
\end{tabular}

\begin{abstract}
Abstrak
Artikel ini ditulis untuk mengkaji isu penipuan tanah yang berlaku dalam urus niaga tanah di Malaysia. Pelbagai modus operandi telah dilakukan oleh penjenayah untuk melakukan penipuan. Dengan modus operandi ini, pihak pejabat tanah telah berjaya diperdaya sehingga menyebabkan berlakunya penipuan dalam urus niaga tanah. Perkara ini telah menimbulkan rasa kebimbangan kepada orang awam tentang jaminan ketuanpunyaan yang merupakan bukti muktamad pemilikan terhadap tanah apabila pendaftaran dilakukan dan juga pemilikan tanah yang ditadbir menurut perundangan Kanun Tanah


Negara (KTN). Kajian yang dilakukan berdasarkan kaedah analisis kes yang telah diputuskan oleh mahkamah. Hasil kajian mendapati pelbagai modus operandi (MO) telah dilakukan oleh penipu dan pelbagai faktor yang mendorong perbuatan penipuan ini. Penulisan ini turut mengutarakan beberapa cadangan penambahbaikan bagi mengekang cubaan penipuan dalam urus niaga tanah.

Kata kunci: Penipuan urus niaga tanah, penipuan identiti, ketuanpunyaan, analisis kes, modus operandi, transaksi

\begin{abstract}
This article was written to examine the issue of land fraud arising from land dealings in Malaysia. Various types of modus operandi have been committed by criminals in this fraud. With these modus operandi, many land offices have been successfully deceived into causing fraudulent land dealings. This has triggered concerns in the public about the legal surety of their proprietorship, which should be legally indefeasible upon legal registration in accordance with the National Land Code (NLC). The study conducted is based on analysis of cases that have been decided by the courts. The findings showed that various types of modus operandi (MO) were attempted by fraudsters and there were various factors that led to the commission of such fraudulent acts. This paper also highlights several suggestions for improvement in order to curb attempted frauds in land dealings.
\end{abstract}

Keywords: Fraudulent land dealing, identity fraud, proprietorship, case analysis, modus operandi, transaction

\title{
PENGENALAN
}

Pengenalan kepada sistem pendaftaran, penyerahan instrumen secara elektronik di pejabat pendaftaran tanah menampilkan beberapa perubahan dalam amalan pendaftaran dan pemasukan urus niaga tanah. Kebimbangan berlakunya perkara yang tidak diingini kerana kebenaran Internet atau akses terhadap sistem pendaftaran tanah dapat membuka peluang kepada penipuan yang berkaitan dengan komputer. Cara ini juga berpotensi menggugat keselamatan dan integriti hak milik. Tidak dapat dinafikan bahawa amalan penipuan berlaku dalam sistem manual. Akan 
tetapi penggunaan teknologi dalam sistem pendaftaran juga membuka peluang berlakunya penipuan apabila terciptanya metode baharu perlakuan penipuan terhadap seseorang individu melalui penipuan identiti (identity fraud) (Harun, 2011, Harun, Hassim \& Hamid, 2013). Penipuan identiti merujuk usaha mengambil maklumat seseorang secara tidak sah tanpa kebenarannya (Christensen, 2004). Kebanyakan kes penipuan dan pemalsuan yang melibatkan kes penipuan identiti, apabila identiti pemilik tanah dipalsukan dengan cara memalsukan kad pengenalan dan juga tandatangan serta pengakuan.

Peningkatan kes penipuan ini turut menimbulkan kebimbangan pemilik tanah terhadap keselamatan harta mereka kerana tanah mereka boleh bertukar milik tanpa disedarinya. Antara faktor yang menyumbang kepada gejala ini termasuklah peningkatan nilai hartanah, tanah terbiar dan kelemahan pengurusan di pejabat tanah.

\section{KONSEP PENIPUAN DALAM URUS NIAGA TANAH MENURUT KTN}

Menurut seksyen $5 \mathrm{KTN}$ urus niaga bermaksud apa-apa transaksi berkenaan dengan tanah beri milik yang dikuatkan di bawah kuasa-kuasa yang diberi oleh Divisyen IV dan apa- apa transaksi yang serupa yang dikuatkuasakan di bawah peruntukan undang-undang tanah terdahulu, tetapi tidak termasuk mana-mana kaveat atau perintah larangan. Dengan erti kata lain, seksyen ini menetapkan tiga elemen penting yang perlu ada dalam sesuatu urus niaga, iaitu (1) wujudnya transaksi; (2) melibatkan tanah beri milik dan (3) transaksi mestilah berbeza daripada kaveat dan Perintah larangan kerana transaksi tidak termasuk dalam definisi urus niaga menurut seksyen $5 \mathrm{KTN}$ kerana kedua-duanya merupakan sekatan terhadap urus niaga yang terkemudian.

Seksyen 340(2)(a) KTN memperuntukkan bahawa pihak yang mendapatkan hak milik secara penipuan maka hak milik tersebut boleh disangkal oleh pemilik asal. Di samping itu juga, jika pihak atau ejennya mengetahui atau menjadi ahli kepada penipuan, maka hak milik pemilik asal menjadi boleh disangkal. Maksudnya, tiada perlindungan diberikan melalui pendaftaran jika seseorang itu telah melakukan penipuan dalam urus niaga tanah. Namun begitu, dalam KTN sendiri tidak menjelaskan secara terperinci tentang perlakuan yang sewajarnya untuk dikatakan 
sebagai penipuan. Menurut Sinnadurai (1996), tafsiran kehakiman perlulah diambil kira untuk mendefinisikan maksud penipuan.

Penipuan sebenar (actual fraud) merupakan elemen yang penting perlu dibuktikan untuk menentukan terdapatnya penipuan. Penipuan sebenar berlaku apabila terdapatnya ketidakjujuran. Menurut Joshua (2006), pemilik baharu mendaftarkan hak milik tanah tersebut atas namanya yang diperoleh melalui penipuan, dan pemilik asal tanah yang ingin mendapatkan hak milik tanah tersebut disangkal. Menurut Hinde, McMorland \& Sim (1978), moral yang buruk juga merupakan jenis penipuan melibatkan ketidakjujuran yang membolehkan hak milik menjadi boleh disangkal.

Di Malaysia, definisi penipuan telah diterima pakai dalam kes PJTV Denson (M) Sdn Bhd lwn Roxy (M) Sdn Bhd, [1980] 2 MLJ 136, Raja Azlan Shah menyatakan bahawa:

"Whether fraud exits is a question of fact, to be decided upon the circumstances of each particular case. Decided cases are only illustrative of fraud. Fraud must mean actual fraud' ie dishonesty of some sort "for which the registered proprietor is a party or privy. - Fraud is the same in all courts, but such expressions as constructive "are...inaccurate; but fraud... implies a willful act, on the part of one, whereby another is sought to be deprived, by unjustifiable means, of what he is entitled. Thus in Waimiha Sawmiling Co Ltd $v$ Waione Timber Co Ltd [1926] AC 101, it was said that if the designed object of a transfer to be cheat a man of a known existing right, that is fraudulent..." (hlm.138).

Kesimpulannya, penipuan sebenar perlu wujud bagi membuktikan berlakunya penipuan dalam urus niaga tanah yang menyebabkan seseorang itu hilang haknya. Di samping itu juga, pemilik baharu merupakan pihak ataupun privy kepada penipuan (Sathiaseelan, 2006, Hang Wu \& Khian Chung, 2001) dan niat untuk menipu perlu dibuktikan bagi memperoleh hak milik atas tanah tersebut. Menurut Harun \& Hassim (2012), penipuan tidak akan berlaku jika tidak disertakan dengan niat untuk menipu bagi tujuan maksud KTN.

Jadual 1 yang berikut adalah antara kes penipuan tanah yang berlaku dalam urus niaga tanah: 
Jadual 1 Kes penipuan dalam urus niaga tanah.

\begin{tabular}{|c|c|}
\hline No. & Kes Penipuan Tanah di Malaysia \\
\hline 1. & Abu Bakar Ismail \& Anor v Ismail Hussin \& Ors Appeals [2007] 3 MLJ 97 \\
\hline 2. & Adorna Properties Sdn Bhd v Boonsom Boonyanit [2001] 1 MLJ 241 \\
\hline 3. & Ahmad Md Daud \& Anor v Che Yah Man [2009] 6 CLJ 530 \\
\hline 4. & $\begin{array}{l}\text { Anthony Bin Lojuta v Clarence Sipain@ Clarence Mojingol \& Ors [2016] } \\
10 \text { MLJ } 603\end{array}$ \\
\hline 5. & Au Meng Nam \& Anor v Ung Yak Chew \& Ors [2007] 5 MLJ 136 \\
\hline 6. & Goh Hooi Yin v Lim Teong Ghee \& Ors [1990] 3 MLJ 23 \\
\hline 7. & Jeyasurian a/l Periasamy v Periasamy a/l Vellasamy [2017] 1 MLJ 638 \\
\hline 8. & Au Meng Nam \& Anor v Ung Yak Chew \& Ors [2007] 5 MLJ 136 \\
\hline 9. & $\begin{array}{l}\text { Chuan Seng \& Anor v Wan Abdul Hamid bin Wan Jaafar \& Ors [2010] } \\
\text { MLJU } 802\end{array}$ \\
\hline 10. & $\begin{array}{l}\text { Krishan Singh a/l Inder Singh v Muniandy a/l Manikkam \& Anor [2010] } 7 \\
\text { MLJ } 173\end{array}$ \\
\hline 11 & Lebai Taib v Abdul Ghani \& Anor [1973] 1 MLJ 109 \\
\hline 12 & Liew Yok Yin v AGS Harta Sdn Bhd [2006] 7MLJ 49 \\
\hline 13 & Mohamed Isa V Haji Ibrahim [1968] 1 MLJ 186 \\
\hline 14. & Mohd Nasir v Moidu Swee Kim [2010] MLJU 1164 \\
\hline 15. & Mok Yong Chuan v Mok Yong Kong \& Anor [2006] 7 MLJ 526 \\
\hline 16. & Nik Mahmood Nik Mat v Chew Kam Leong [2011] 1 LNS 202 \\
\hline 17. & $\begin{array}{l}\text { OCBC Bank (M) Bhd v Pendaftar Hak Milik Negeri Johor Darul Takzim } \\
\text { [1999]2 MLJ } 511\end{array}$ \\
\hline 18. & Ong Lian v Tan Eng Jin (1917) 1 FMSLR 325 \\
\hline 19. & Ong Lock Cho V Quek Shin \& Sons Ltd (1941) MLJ 88 \\
\hline 20. & PJTV Denson (M) Sdn Bhd lwn Roxy (M) Sdn Bhd. [1980] 2 MLJ 136 \\
\hline 21. & Quah Hong Lian Neo v Teong Teck [1936] MLJ 203 \\
\hline 22. & $\begin{array}{l}\text { Rabiah bt Ani v Samsi bin Hj Hasim (t/a Syarikat Perniagaan Jaya) \& Anor } \\
\text { [2011] } 7 \text { MLJ } 225\end{array}$ \\
\hline 23. & Shayo (M) Sdn Bhd v Nurlieda Sidek \& Ors [2013] 1 CLJ 153 \\
\hline 24. & $\begin{array}{l}\text { Soon Poy Yong@ Soon Puey Yong v Westport Properties Sdn Bhd \& Ors } \\
\text { 2015]11 MLJ } 196\end{array}$ \\
\hline 25. & $\begin{array}{l}\text { Subramaniam a/l Ns Dhurai v Sandrakasan a/l Retnasamy \& Ors [2005] } 6 \\
\text { MLJ } 120\end{array}$ \\
\hline
\end{tabular}




\section{MODUS OPERANDI (MO) PENIPUAN TANAH}

Berdasarkan kepada kes yang telah diputuskan oleh mahkamah di Malaysia, beberapa modus operandi atau cara melakukan penipuan tanah adalah seperti dalam Jadual 2.

Jadual 2 Modus operandi penipuan urus niaga tanah.

\begin{tabular}{|c|c|c|}
\hline No. & Modus Operandi & Urus niaga \\
\hline 1 & Pemalsuan Surat Wakil Kuasa & $\begin{array}{l}\text { Gadaian, } \\
\text { Pindah Milik }\end{array}$ \\
\hline 2 & Pemalsuan Tanda tangan & $\begin{array}{l}\text { Gadaian, } \\
\text { Pindah Milik }\end{array}$ \\
\hline 3 & Pemalsuan Memorandum Pindah Milik & $\begin{array}{l}\text { Pindah } \\
\text { Milik, } \\
\text { Gadaian }\end{array}$ \\
\hline 4 & Penipuan oleh Peguam & $\begin{array}{l}\text { Pindah } \\
\text { milik, } \\
\text { Gadaian }\end{array}$ \\
\hline 5 & Penipuan Pembetulan Nama Tuan Punya Tanah & Pindah milik \\
\hline 6 & Penipuan Hartanah Amanah & Pindah Milik \\
\hline 7 & Penipuan Perintah Mahkamah & Pindah Milik \\
\hline 8 & $\begin{array}{l}\text { Penipuan dalam Sistem Pendaftaran Tanah } \\
\text { Berkomputer }\end{array}$ & Pindah Milik \\
\hline 9 & Penipuan Perjanjian jual beli (PJB) & $\begin{array}{l}\text { Pindah } \\
\text { Milik, } \\
\text { Gadaian }\end{array}$ \\
\hline 10 & Pemalsuan Dokumen Hak milik (geran) & Pindah Milik \\
\hline 11 & Penipuan Jual Beli Tanah Rizab Melayu & Pindah Milik \\
\hline 12 & Penipuan oleh agen atau broker & Pindah Milik \\
\hline 13 & Penipuan oleh ahli keluarga terhadap warga tua & Pindah Milik \\
\hline
\end{tabular}


Pelbagai modus operandi dilakukan oleh penipu. Contohnya mangsa membeli tanah dengan penipu dan bayaran penuh pembelian telah dibuat. Namun begitu, kemudiannya, pembeli mendapati tanah tersebut milik orang lain. Sebahagian penipu menawarkan harga yang lebih murah berbanding dengan harga pasaran kepada mangsa dengan mengemukakan geran palsu, atau memalsukan identiti pemilik tanah. Penipuan sebegini boleh dilakukan oleh broker tanah dan peguam, dan juga ahli keluarga terdekat, terutamanya terhadap orang tua atau warga tua. Peluang penipuan terbuka apabila penipu mendapati geran lama tuan punya tanah tiada nombor kad pengenalan. Pada kebiasaannya penipu mendekati warga tua yang mempunyai nama yang sama seperti tertera dalam geran tanah untuk menyamar seolah-olah sebagai tuan punya tanah yang sebenar.

Modus operandi yang dilakukan ini hanya disedari oleh pemilik tanah asal (i) apabila mereka hendak membayar cukai tanah, (ii) apabila pembangunan berlaku atas tanah mereka, (iii) semasa penyerahan borang pindah milik tanah (Borang 14A) atau (iv) apabila semakan atau carian di pejabat tanah telah dilakukan.

\section{FAKTOR BERLAKUNYA PENIPUAN DALAM URUS NIAGA TANAH}

Analisis daripada kajian kes yang diputuskan oleh mahkamah didapati terdapat pelbagai modus operandi dikesan dan dikenal pasti telah berjaya dilakukan oleh penipu dalam penipuan urus niaga tanah. Oleh yang demikian dapat dirumuskan bahawa antara faktor yang mendorong berlakunya penipuan ini adalah seperti yang berikut:

\section{(1) Faktor manusia}

Daripada analisis kes mahkamah di atas, faktor manusia merupakan punca berlakunya penipuan tanah seperti mudah terpengaruh, mementingkan diri sendiri, faktor kerakusan serta sifat tamak manusia. Penipu mencari jalan pintas untuk mendapatkan kekayaan dengan cara segera dan mudah. Pelbagai cara yang digunakan oleh penipu untuk tujuan menipu seperti menyamar sebagai tuan punya tanah, sebagai pegawai kerajaan, Pegawai Daerah, Pegawai Pejabat Tanah dan Galian. Mereka memujuk mangsa untuk menjadi rakan kongsi untuk membeli 
tanah dan berjanji keuntungan akan dikongsikan bersama. Penipuan oleh ahli keluarga terdekat terutamanya kepada warga tua juga berlaku apabila mangsa dipujuk untuk memasukkan duit dalam akaun penipu kononnya sebagai bayaran pendahuluan atau bayaran untuk proses permohonan. Mereka kemudiannya menghilangkan diri dan gagal dikesan. Mereka juga mungkin meyakinkan mangsa untuk mempercayai bahawa mereka telah mendapatkan kelulusan permohonan tanah dengan meniru tanda tangan pegawai berkuasa yang meluluskan permohonan. Di samping itu, tidak dinafikan juga sikap manusia yang mudah dipengaruhi oleh harta benda dan kekayaan turut menjadi punca berlakunya penipuan tanah (Ismail, 2009).

Di samping itu juga, daripada analisis di atas juga, didapati kecuaian pembeli tanah seperti sikap mudah terpengaruh turut menjadi faktor penipuan dilakukan. Pada peringkat awal, urusan perniagaan yang dibuat oleh penipu adalah dengan memujuk mangsa untuk menyewa atau membeli tanah. Kemudian penipu memujuk mangsa untuk berkongsi pembelian tanah dengan cara menggunakan dokumen hak milik palsu. Mangsa yang terpedaya mengeluarkan modal untuk membeli tanah berkenaan. Penipuan turut dilakukan melibatkan tanah yang tidak wujud dalam urusan jual beli tanah. Terdapat juga kes penipu mengemukakan dokumen hak milik tanah palsu asal, maka pembeli akan berasa yakin untuk meneruskan urusan pindah milik tanah. Di samping itu juga, sikap sesetengah pembeli tanah yang tidak menyelidik status hak milik atau tuan punya tanah tersebut. Terdapat kes penipu menyamar sebagai pemilik tanah dan menggunakan kad pengenalan sementara semasa perjanjian jual beli tanah ditandatangani. Tiada pencarian maklumat tentang tanah dilakukan di pejabat tanah oleh bakal pembeli. Malahan harga tanah yang ditawarkan jauh lebih rendah berbanding dengan nilai harga di pasaran. Sikap sesetengah bakal pembeli yang terburu-buru untuk mendapatkan harga rendah yang ditawarkan ini, dan terus menyempurnakan urusan jual beli tanah tanpa melakukan sebarang penyiasatan atau mengambil langkah berjaga-jaga untuk mengetahui siapakah tuan punya tanah dan ketulenan dokumen pindah milik turut menyumbang kepada penipuan tanah mudah dilakukan.

Di samping itu juga, mangsa kebanyakannya tidak mengetahui prosedur urusan jual beli tanah dan tidak merujuk atau mendapatkan pandangan daripada pihak ketiga apabila melakukan pindah milik atau pembelian tanah. Sejajar dengan yang dinyatakan oleh Ain (2008) bahawa 
kes penipuan mudah dilakukan apabila carian rasmi tidak dilakukan oleh pembeli di pejabat tanah terlebih dahulu. Di samping itu juga, bakal pembeli menerima tawaran harga di bawah pasaran tanpa menyedari kesan perbuatannya itu.

\section{(3) Kelemahan pengurusan di pejabat tanah}

Kekurangan pengetahuan dalam kalangan kakitangan pejabat tanah untuk mengenal pasti dokumen yang asli yang dikemukakan dalam jual beli tanah. Setiap dokumen yang dihantar hanya dipastikan lengkap dan layak untuk didaftarkan. Kebanyakan mereka tidak dilatih atau didedahkan untuk mengesan jenis penipuan yang berlaku dalam urusan urus niaga tanah (Zakariah, 2020). Sesetengah kakitangan menguruskan perihal pendaftaran tanah berdasarkan pengetahuan yang diperoleh daripada pengalaman sendiri ataupun daripada rakan sekerja yang telah lama bekerja. Walaupun mereka mengikuti kursus pengurusan tanah tetapi tidak memadai untuk meliputi keseluruhan aspek urusan berkaitan dengan tanah.

Kemasukan kakitangan ke bilik kebal juga haruslah diperketat kerana berlakunya kehilangan dokumen dan kebocoran maklumat yang dapat dikesan apabila tiada kawalan bagi kemasukan dan pengambilan dokumen dari bilik kebal tersebut.

\section{(3) Tidak teliti dalam menentukan ketulenan dokumen dan perintah mahkamah yang dikemukakan}

Penipuan dalam urus niaga tanah mudah dilakukan kemungkinan disebabkan kurangnya semakan dan penelitian terhadap dokumen yang dikemukakan oleh kakitangan pejabat tanah. Menurut Othman (2008) dalam penulisannya, penggunaan perintah mahkamah untuk mendaftar pemilik baharu juga menjadi modus operandi untuk pelakuan jenayah penipuan. Perintah mahkamah ini digunakan sebagai instrumen urusan tukar hak milik tanah dengan memasukkan nombor kes yang didaftarkan di mahkamah dan meletakkan cop timbul mahkamah seolah-olah perintah mahkamah tersebut adalah tulen. Bagi kakitangan pejabat tanah yang tiada pengetahuan tentang urusan mahkamah tentang rupa bentuk perintah mahkamah menganggap perintah itu sebagai benar. Oleh itu, ciri-ciri penting yang terkandung dalam perintah mahkamah tidak diambil kira. 
Oleh yang demikian, kakitangan pejabat tanah perlulah mempunyai pengetahuan tentang ciri-ciri penting yang kebiasaannya terdapat pada perintah mahkamah seperti nama hakim yang mengeluarkan perintah, nombor rujukan saman, cop timbul mahkamah dan mahkamah yang bertanggungjawab (mahkamah tinggi).

\section{(4) Ketidakpatuhan kepada prosedur dan kelemahan undang-undang.}

Dapatan daripada analisis kes yang diputuskan, terdapat juga kes yang tiada permohonan Dokumen Hak Milik Keluaran Komputer (DHKK) yang dibuat oleh pemilik tanah tetapi terdapat pendaftaran hak milik dilakukan atas nama pemilik baharu. Mengikut prosedur, pemilik tanah hendaklah menyerahkan dokumen hak milik asal atau geran lama terlebih dahulu sebelum DHKK dikeluarkan. Oleh itu, pendaftaran hak milik ini adalah bertentangan dengan kehendak Jadual Keempat Belas KTN.

Pendaftar juga mempunyai kuasa yang terhad untuk mendaftarkan sesuatu urus niaga tanah menurut KTN. Tugasnya hanyalah memastikan sama ada sesuatu instrumen itu layak untuk didaftarkan seperti yang diperuntukkan menurut seksyen 298 KTN. Selagi instrumen itu lengkap dan layak untuk didaftarkan maka perlulah bagi Pendaftar untuk mendaftarkan urus niaga tersebut. Maka bukanlah menjadi tanggungjawabnya untuk menyiasat sesuatu instrumen itu merupakan penipuan atau urus niaga yang tidak lengkap (Ismail, 2011).

Tanah di kawasan strategik yang bernilai tinggi dan terbiar menjadi tumpuan utama para penipu melakukan penipuan tanah. Tuan tanah hanya mengetahui tanah mereka telah bertukar tangan kepada pemilik baharu apabila semua urusan pindah milik tanah dilakukan. Sememangnya, pihak pejabat tanah boleh mengambil tindakan dengan merampas tanah yang tidak diusahakan menurut seksyen 129 KTN. Namun begitu, kebanyakan tindakan tidak diambil oleh pejabat tanah yang menyebabkan banyak tanah tidak dibangunkan dan terbiar akibat kelemahan penguatkuasaan undang-undang.

\section{(5) Tiada integriti dan akauntabiliti}

Analisis kes di atas turut mendapati bahawa kata laluan (password) yang sepatutnya dikhususkan kepada seorang penanggungjawab dikongsikan 
bersama-sama dengan pegawai dan kakitangan lain di pejabat tanah. Keadaan ini memudahkan kegiatan penipuan tanah dilakukan apabila terdapat kerjasama antara sesama mereka. Di samping itu juga, terdapat peguam yang menggunakan dokumen pindah milik tanah yang ada dalam jagaannya untuk kepentingan dirinya sendiri. Keadaan ini menunjukkan sikap tidak amanah yang ada pada diri peguam lantas mendorongnya melakukan penipuan tersebut. Menurut Hang Wu dan Khian Chung (2011) dalam kajian mereka menyatakan bahawa klien kebiasaannya mudah terdedah dengan penipuan apabila dokumen hak milik tanah berada dalam jagaan peguam yang tidak beretika dan tiada integriti. Menurut mereka, peguam sepatutnya tidak dibenarkan untuk menyimpan dokumen hak milik tanah kliennya tanpa sebab yang munasabah. Oleh itu, mereka menegaskan agar satu arahan perlu diwujudkan untuk mengembalikan dokumen hak milik tanah kepada klien dalam masa dua minggu selepas penyempurnaan transaksi. Kegagalan untuk seseorang peguam berbuat demikian, tanpa sebab-sebab yang munasabah, boleh dikenakan tindakan disiplin.

\section{(6) Peguam yang tidak berhati-hati untuk mengakui saksi sesuatu urus niaga tanah yang disempurnakannya}

Tidak dinafikan sesetengah peguam yang tidak menghendaki pihak yang ingin menyempurnakan instrumen urus niaga tampil atau hadir bersamasamanya untuk menandatangani sesuatu surat cara di hadapannya. Perlakuan ini juga memudahkan penipuan berlaku dalam urus niaga tanah. Mengikut seksyen $211 \mathrm{KTN}$, penyempurnaan mana-mana instrumen urus niaga hendaklah disaksikan oleh pegawai-pegawai atau orang lain yang tersenarai dalam Jadual Kelima termaksuklah peguam. Menurut Fook Hing (2011) dalam kajiannya menegaskan terdapat peguam di Malaysia tidak menghendaki pihak yang menyempurnakan sesuatu instrumen untuk menandatangani dokumen urus niaga di hadapannya, walaupun cara begini membolehkan sesuatu instrumen menjadi tidak sah di bawah seksyen 340(2)(b) KTN. Kebanyakan mereka menyerahkan tugas tersebut kepada kerani untuk mengesahkan identiti klien yang berurusan dengan mereka. Hal ini mengundang berlakukan penipuan dalam kalangan peguam. 


\section{CADANGAN PENYELESAIAN}

Antara cadangan penyelesaian penipuan dalam urus niaga tanah adalah seperti yang berikut:

Cabaran ke arah mencapai tadbir urus yang baik (good governance) adalah perlu untuk membanteras kejadian penipuan dalam urus niaga tanah yang tidak berkesudahan. Untuk mencapai pentadbiran yang baik (good management), perkara utama yang perlu diselesaikan ialah ketelusan (transparency) dan akauntabiliti dalam pentadbiran (Mohamad, 2007). Oleh itu, usaha untuk membentuk dan menghidupkan tadbir urus yang baik akan terencat jika gejala penipuan tidak ditangani dengan bersungguh-sungguh oleh semua pihak sama ada kerajaan atau swasta, pemimpin atau rakyat jelata. Penyalahgunaan kuasa oleh para pegawai akan memudaratkan kepercayaan rakyat tentang ketelusan pejabat tanah. Kerajaan haruslah berfungsi sebagai entiti yang mengamalkan governans yang baik untuk mendapat kepercayaan rakyat terhadap pejabat tanah tentang keselamatan hak milik tanah mereka (Mohd Tap, 2012). Dengan erti kata lain, tadbir urus yang baik ialah jantung kepada pentadbiran tanah yang baik. Pentadbiran tanah yang berjaya memerlukan akauntabiliti, institusi yang stabil, telus dan bebas daripada sebarang bentuk penipuan dan rasuah (Choon \& Hussin, 2012). Di samping itu juga, ruang pemantauan yang lebih intensif disarankan dapat diwujudkan bagi meminimumkan kegiatan penipuan dalam pentadbiran kerajaan (Zainuddin, et al. 2010).

Daripada analisis kes, sesetengah peguam tidak mengehendaki pihak yang menyempurnakan sesuatu instrumen untuk hadir dan menandatangani dokumen urus niaga di hadapannya. Menurut undangundang Islam, majlis al-aqd merupakan satu elemen untuk menjadikan sesuatu kontrak itu sah dan mengehendaki pihak yang berkontrak bersama-sama hadir secara bersemuka (face-to-face basis) dalam sesi kontrak yang hendak dilaksanakan (Nor Muhamad, 2008, Alzaagy, 2011, Razali, 2010). Perkara ini perlu ditekankan dalam pelaksanaan urusan jual beli tanah bagi memastikan kehadiran pihak yang berkontrak apabila hendak menandatangani surat cara yang dikemukakan bagi menghindari penipuan identiti berlaku.

Kempen kesedaran dan pemakluman kepada masyarakat menerusi media elektronik dan media sosial. tentang bahaya penipuan dalam urus niaga dan jual beli tanah juga wajar diusahakan oleh pihak yang 
berkenaan. Langkah-langkah yang sepatutnya dilakukan oleh pemilik tanah, pembeli tanah dan penjual tanah untuk memastikan tanah yang diurusniagakan adalah selamat dan dilindungi daripada penipuan oleh mereka yang tidak bertanggungjawab. Usaha ini dapat meningkatkan pengetahuan masyarakat dan kesiapsiagaan mereka terhadap penipuan dalam urus niaga tanah yang mungkin akan mereka hadapi.

Kakitangan pejabat tanah juga haruslah memperlengkap diri mereka dengan menambahkan ilmu pengetahuan dari segi undang-undang tanah, kepatuhan kepada prosedur urus niaga tanah, serta penelitian dan semakan terhadap dokumen yang dikemukakan haruslah dipertingkatkan. Mereka juga perlu didedahkan tentang cara penipuan yang kebiasaanya dilakukan oleh penipu dalam menjayakan misi mereka. Dengan adanya sikap lebih berhati-hati dan waspada dalam diri kakitangan pejabat tanah dapatlah mempertingkatkan keselamatan hak milik kepada pihak yang berurusan dengan pejabat tanah.

Di samping itu juga, dengan ketiadaan remedi yang diaward kepada mangsa penipuan daripada kes yang dibincangkan, penulis berpendapat adalah wajar bagi pihak kerajaan untuk memikirkan satu bentuk remedi untuk diberikan kepada mangsa penipuan tanah. Oleh itu, KTN haruslah dipinda bagi memasukkan prinsip insurans agar dapat memelihara keselamatan hak milik dan memberikan perlindungan kepada mangsa penipuan tanah di Malaysia.

\section{KESIMPULAN}

Masalah penipuan akan bertambah kompleks selari dengan perkembangan negara yang pesat dan nilai hartanah yang semakin meningkat. Sehubungan dengan itu, pihak pentadbir tanah dan pihak yang terlibat perlu memainkan peranan yang lebih proaktif untuk mengurangkan ruang untuk aktiviti penipuan. Oleh yang demikian tadbir urus yang baik, perubahan dalam diri manusia itu sendiri dan reformasi undang-undang serta ketelusan prosedur tanpa kerenah birokrasi adalah perlu dalam pentadbiran tanah pada masa sekarang bagi menjamin kebajikan dan perlindungan kepada mereka yang berurusan dengan pejabat tanah. Menurut Zakariah (2020), penambahbaikan terhadap kualiti dalam pentadbiran tanah di Malaysia adalah perkara penting yang perlu diambil perhatian untuk memelihara ketelusan pejabat tanah itu sendiri. Tambahan pula, KTN merupakan akta yang berkaitan dengan urusan tanah di Malaysia memerlukan pindaan 
yang sewajarnya bagi memberikan ruang kepada keselamatan hak milik serta perlindungan kepada mereka yang terkesan akibat perbuatan penipuan oleh pihak yang tidak bertanggungjawab agar jaminan keadilan diberikan kepada pihak yang terlibat.

\section{RUJUKAN}

Abu Bakar Ismail \& Anor v Ismail Hussin \& Ors Appeals [2007] 3 MLJ 97

Adorna Properties Sdn Bhd v Boonsom Boonyanit [2001] 1 MLJ 241

Ahmad Md Daud \& Anor v Che Yah Man [2009] 6 CLJ 530

Ain, A.H. (2008). Penipuan dalam urusan tanah- kelemahan, amalan terbaik dan cadangan bagi mengatasinya. Jurnal Instun, 1(2), 13-34.

Alzaagy, A. (2011). Contracting concept of meeting place' in islamic law: is there a room for its possible implementation in internet transaction? Masaryk University Journal of law and Technology, 5(2),147.

Anthony Bin Lojuta v Clarence Sipain @ Clarence Mojingol \& Ors [2016] 10 MLJ 603

Au Meng Nam \& Anor v Ung Yak Chew \& Ors [2007] 5 MLJ 136

Choon, T.L., Hussin, K. (2012). Towards E- Government's 3D Property. International Journal of Scientific \& Engineering Research, 3(3), 5.

Christensen, S. (2004) Electronic land dealings in Canada, New Zealand and the United Kingdom: Lessons for Australia. Murdoch University Electronic Journal Of Law, 11(4), 7-8.

Chuan Seng \& Anor v Wan Abdul Hamid bin Wan Jaafar \& Ors [2010] MLJU 802 Fook Hing, A.W. (2011). Recent Federal Court's decision on section 340 of National Land Code 1965: Tan Ying Hong v Tan Sian San \& Ors - Are Landowners and Banks Secured? Praxis, Jan-Mar 2011, 8.

Goh Hooi Yin v Lim Teong Ghee \& Ors [1990] 3 MLJ 23

Hang Wu, T., Khian Chung, L. (2011). A law which favours forgers? Land fraud in two torrens jurisdictions. Australian Property Law Journal, 19(2), 14.

Harun, N., Hassim, J.Z. (2012). Frod berkaitan kepentingan yang tidak berdaftar: Satu analisa. Kertas kerja yang dibentangkan di Seminar Progress 2012: Postgraduate Research Seminar, Fakulti Sains Sosial dan Kemanusiaan, UKM.

Harun,N. (2011). Kanun Tanah Negara 1965: Adakah melindungi pihak berkepentingan dalam pemilikan hartanah? Kertas kerja yang dibentangkan di International Conference On Consumer Law 2011 (CONLAW 2011): Social Justice and Consumer Law. 'Equatorial Hotel, Bangi : Selangor.

Harun, N., Hassim, J.Z. N.A., Hamid. (2013). Penipuan, rasuah dan pencurian maklumat dalam urusniaga tanah: cabaran dan penyelesaian. Kanun: Jurnal Undang-undang, 25(2),159-184. 
Hinde, G.W., McMorland, D.W., Sim, P.B.A. (1978). Land Law (volume 1). Butterworths of New Zealand Ltd.,

Ismail, M.S. (2011). Measures undertaken to safeguard against fraud in land dealings. Jurnal Pentadbiran Tanah, 1(1), 92.

Ismail. A.N. (2009). Penipuan dalam Urusan Pindahmilik Tanah, Kajian Kes: Jabatan Ketua Pengarah Tanah dan Galian (BA Thesis tidak diterbitkan). Universiti Teknologi Malaysia.

Jeyasurian a/l Periasamy v Periasamy a/l Vellasamy [2017] 1 MLJ 638

Krishan Singh a/l Inder Singh v Muniandy a/1 Manikkam \& Anor [2010] 7 MLJ 173

Lebai Taib v Abdul Ghani \& Anor [1973] 1 MLJ 109

Liew Yok Yin v AGS Harta Sdn Bhd [2006] 7MLJ 49

Mohamad, N.A. (2007). Advocating Islamic values and ethics in land administration. Shariah law Report, 2, 11.

Mohamed Isa V Haji Ibrahim [1968] 1 MLJ 186

Mohd Nasir v Moidu Swee Kim [2010] MLJU 1164

Mohd Tap, F. (2012). Rasuah: cabaran besar wujudkan tadbir urus baik. Majalah Milenia Muslim, 41.

Mok Yong Chuan v Mok Yong Kong \& Anor [2006] 7 MLJ 526

Nik Mahmood Nik Mat v Chew Kam Leong [2011] 1 LNS 202

Nor Muhamad, N.H. (2008). Aplikasi sains dan teknologi dalam transaksi muamalah islam: rujukan kepada rukun-rukun akad mengikut perspektif undang- undang kontrak Islam. Jurnal Teknologi, 49(E), 85.

OCBC Bank (M) Bhd v Pendaftar Hak Milik Negeri Johor Darul Takzim [1999] 2 MLJ 511

Ong Lian v Tan Eng Jin (1917) 1 FMSLR 325

Ong Lock Cho V Quek Shin \& Sons Ltd (1941) MLJ 88

Othman, S. (2008). Penipuan dalam urusan tanah: Isu dan penyelesaian. Jurnal INSTUN, 1(2), 1-12.

PJTV Denson (M) Sdn Bhd lwn Roxy (M) Sdn Bhd, [1980] 2 MLJ 136

Quah Hong Lian Neo v Teong Teck [1936] MLJ 203

Rabiah bt Ani v Samsi bin Hj Hasim (t/a Syarikat Perniagaan Jaya) \& Anor [2011] 7 MLJ 225

Razali, S.S. (2010). Islamic law of contract. Cengage Learning Asia Pte Ltd.

Sathiaseelan, J.K. (2006). Prinsip-prinsip Penting Perundangan Tanah di Malaysia. Malayan Law Journal.

Shayo (M) Sdn Bhd v Nurlieda Sidek \& Ors [2013] 1 CLJ 153

Sinnadurai, V. (1996). Jual beli harta tanah di Malaysia. Dewan Bahasa dan Pustaka.

Soon Poy Yong@ Soon Puey Yong v Westport Properties Sdn Bhd \& Ors 2015] 11 MLJ 196 
Subramaniam a/l Ns Dhurai v Sandrakasan a/l Retnasamy \& Ors [2005] 6 MLJ 120

Zainuddin, A., et al. (2010). Korupsi dalam budaya politik Malaysia: Satu tinjauan. Kertas kerja yang dibentangkan di International Conference On Public Policies \& Social Sciences, Sp Inn Hotel, Sungai Petani, Kedah.

Zakariah, Y., Samsudin, S., Ngadiman, N. (2020). An overview of the fraud and forgery challenges in land registrations system. European Journal of Molecular \& Clinical Medicine, 7(03), 274-282. 